\title{
PMTCT Interventions and Outcome of Babies Born to HIV Positive Mothers: A Retrospective Study at a Secondary Health-Care Facility in Warri, Delta State, Nigeria
}

\author{
Victor Omote $^{1}$, Henry Ukwamedua ${ }^{1}$, Johnson Etaghene ${ }^{2}$, Matthew Ejike Oseji ${ }^{3}$, \\ Imaria Celia Agwai ${ }^{4}$, Harrison Agbroko ${ }^{5}$ \\ ${ }^{1}$ Department of Laboratory Services, Central Hospital, Warri, Nigeria \\ ${ }^{2}$ Department of Laboratory Services, Ministry of Health Delta State, Asaba, Nigeria \\ ${ }^{3}$ Department of Environmental Health Sciences, University of Ibadan, Ibadan, Nigeria \\ ${ }^{4}$ Department of Epidemiology and Medical Statistics, University of Ibadan, Ibadan, Nigeria \\ ${ }^{5}$ Department of Laboratory Services, Nigerian National Petroleum Cooperation Medical Centre, Warri, Nigeria
}

Email address:

boyoo4pre $a$ gmail.com (Victor Omote)

\section{To cite this article:}

Victor Omote, Henry Ukwamedua, Johnson Etaghene, Matthew Ejike Oseji, Imaria Celia Agwai, Harrison Agbroko. PMTCT Interventions and Outcome of Babies Born to HIV Positive Mothers: A Retrospective Study at a Secondary Health-Care Facility in Warri, Delta State, Nigeria. American Journal of Laboratory Medicine. Vol. 3, No. 5, 2018, pp. 40-43. doi: 10.11648/j.ajlm.20180305.11

Received: August 10, 2018; Accepted: October 26, 2018; Published: November 26, 2018

\begin{abstract}
Mother to child transmission (MTCT) of the AIDS virus remains a persistent means for HIV acquisition and accounts for most cases of paediatric HIV infection. Maternal viral load, antiretroviral therapy for mother and infants, infant feeding pattern and mode of delivery have been implicated as factors that affects MTCT rates. The study evaluated the efficacy of the various PMTCT interventions in relation to HIV status of the babies. Early Infant Diagnosis (EID) register of exposed infants seeking care from January 2015-December 2016 was retrieved and reviewed. Data on mother's antiretroviral therapy (ART) status, infants ART status, sex, feeding pattern and HIV status were extracted, recorded an analyzed using SPSS 23 and results expressed in simple frequency and percentage. Statistical association was assayed for using Chi-square and Fisher's exact test. A total of 249 mother and infant pairs took part in the study. Approximately (50.2\%) of the infants were females and virtually all (95.6\%) of the participating mothers were on ART. Likewise, almost all $(94.0 \%)$ of the infants were placed on ART while majority of them (71\%) were exclusively breastfed. An incidence rate of $4.4 \%$ (11/249) for MTCT of the AIDS virus was recorded while variables such as maternal ART status, infant ART status and infant feeding pattern showed strong association with MTCT. Findings from this study revealed a reduced prevalence for the study region when compared to other regions and a hope for the complete eradication of MTCT of HIV when PMTCT interventions and strategies are properly implemented and utilized.
\end{abstract}

Keywords: Prevalence, Mother-to-Child-Transmission, PMTCT Interventions HIV, Infants, Warri, Delta State

\section{Introduction}

HIV infection among women of child bearing age and mother to child transmission (MTCT) of HIV in Nigeria remains a major health burden [1] M-T-C-T is responsible for about $90 \%$ of paediatric HIV cases in Africa [2] with about $14.3 \%$ of these cases resulting to death before the age of 15 years [3]. Incidence of M-T-C-T without interventions varies from $25-45 \%$ (5-10\% during pregnancy, $15-20 \%$ during delivery and 5-10\% during breastfeeding) [4].

Acquisition of the HIV virus from the mother may occur via three known mechanisms. These include In utero (microtransfusion of viremic maternal blood across the placenta resulting from break down of placenta integrity), Intra-patum (contact of infant mucosal membrane with HIV in maternal 
blood and secretions during birth process) and Post-patum (viral acquisition via breast milk) [4].

Prevention of Mother to Child Transmission (PMTCT) interventions have been responsible for gross reduction of MTCT and corresponding mortalities to about less than $1 \%$ in Europe and America [5] and from 570,000 cases in 2003 to an estimated 110,000 in 2015 within the 21 Global Plan Priority Countries in Sub-Saharan Africa [6].

Prevention of newer HIV infection among women of child bearing age, discouraging unintended pregnancy among HIV-infected women, preventing transmission of HIV to infants from positive mothers and lastly ensuring the availability of appropriate treatment, care and support for women, children and family are component of the four prong comprehensive approach to PMTCT.

About 1,216 PMTCT centers are distributed across Nigeria. Theses center render services ranging from the provision of ART for both mother and infant, screening pregnant women during antenatal, advocating for Caesarian section for HIVpositive pregnant women before the onset of labor or rapture of membrane, avoidance of breast feeding and health education on maternal and child welfare [4].

Effective implementation of PMTCT interventions in the western world has reduced the incidence of MTCT that it is no longer a public health issue (incidence lesser than $1 \%)$. Even in low income and middle income countries like Botswana, Tanzania and Cote d' Ivoire, increased quality of PMTCT services have reduced MTCT to between $2-4 \%$ [7].

There has been increase in the number of PMTCT centers and their services across Nigeria and in Delta State in particular. However, there are no or few reports on the impact of these PMTCT centers and their interventions in relation to the transmission of the AIDS virus from HIVinfected mothers to their infants Thus, this study seeks to evaluate the incidence of paedatric HIV and effect of PMTCT interventions among exposed babies seeking care at Central Hospital Warri.

\section{Materials and Methods}

\subsection{Study Design and Area}

This is a retrospective study carried out at Central Hospital Warri. Central Hospital Warri is a 350 bed secondary facility that serves as a referral center for most parts of Delta South and Central, Edo state and parts of Bayelsa state. Warri is the most populated city in Delta state and also serve as its economic nerve. It is a multi-ethnic city with residents ranging from fishermen and street hawkers to top class civil servants and business executives.

\subsection{Inclusion and Exclusion Criteria}

All exposed babies younger than 18 months attending Central Hospital Warri from January 2015 through December 2016 were eligible for the study. Only those with incomplete data on maternal ART status, infant's ART status, infant's sex, infant's feeding pattern and HIV PCR results were excluded from the study.

\subsection{Data Collection and Management}

A total of 249 participants (mother and infant pair) were eligible for the study. Data on maternal ART status, infant ART status, infant's sex, infant's feeding pattern and HIV PCR results were recovered from the Early Infant Diagnosis (EID) register. This data were reviewed and analyzed using SPSS 23. They were expressed as simple frequency and percentage while statistical association was assayed for using Pearson's Chi-square and Fisher's exact test at confidence limit of $95 \%$ and p-values lesser than 0.05 termed to be significant.

\section{Results}

Of the 249 mother and infant pair that participated in the study, 238 mothers were on ART (95.6\%) while $11(4.4 \%)$ were not on ART. $179(71.9 \%)$ of the babies were exclusively breastfeed while $17(6.8 \%)$ were mix fed. 234 $(94.0 \%)$ of the children were on ART while $125(50.2 \%)$ were females. Table 1 summarizes the characteristics of the studied population.

Table 1. Characteristics of the studied population.

\begin{tabular}{lll}
\hline Variables & Frequency & Percentage \\
\hline Mother on ART & 238 & \\
Yes & 11 & 95.6 \\
No & & 4.4 \\
Infant's feeding pattern & 179 & \\
Exclusive breast feeding & 53 & 71.9 \\
Commercial formula feeding & 17 & 21.3 \\
Mixed-feeding & & 6.8 \\
Infants on ART & 234 & \\
Yes & 15 & 94.0 \\
No & & 6.0 \\
Infant's sex & 124 & 49.8 \\
Male & 125 & 50.2 \\
Female & & \\
\hline
\end{tabular}

A general incidence of $4.4 \%$ (11 out of 249) was recorded in this study. Table 2 .

Table 2. Prevalence of mother to child transmission rate.

\begin{tabular}{lll}
\hline HIV PCR Result & Frequency & Percentage \\
\hline Positive & 11 & 4.4 \\
Negative & 238 & 95.6 \\
Total & 249 & 100 \\
\hline
\end{tabular}

Infants born to mothers on ART had a MTCT rate of $1.3 \%$ (3 out of 238), infants that are on ART gave a prevalence of $1.3 \%$ (3 out of 234 ), while infants that were mix-fed gave a MTCT rate of $17.6 \%$. Table 3. Analysis for statistical association between studied variables and MTCT rates gave significant $\mathrm{p}$-values except for the sex of the infant. Table 3. 
Table 3. MTCT rates in relation to study variables.

\begin{tabular}{llll}
\hline Variables & Tested (n) & Positive n (\%) & P-values \\
\hline $\begin{array}{l}\text { Maternal ART status } \\
\text { Yes }\end{array}$ & 238 & $3(1.3)$ & 0.00 \\
No & 11 & $8(72.7)$ & \\
$\begin{array}{l}\text { Infant ART status } \\
\text { Yes }\end{array}$ & 234 & $3(1.3)$ & 0.00 \\
No & 15 & $8(53.3)$ & \\
$\begin{array}{l}\text { Infant feeding pattern } \\
\text { Exclusive breast feeding }\end{array}$ & 179 & $6(3.4)$ & 0.02 \\
Commercial formula & 53 & $2(3.8)$ & \\
$\begin{array}{l}\text { Mixed feeding } \\
\text { Sex of infant }\end{array}$ & 17 & $3(17.6)$ & \\
$\begin{array}{l}\text { Male } \\
\text { Female }\end{array}$ & 124 & $4(3.2)$ & 0.37 \\
\hline
\end{tabular}

\section{Discussion}

The MTCT rate of $4.4 \%$ recorded in this study, is in contrast to the $13.7 \%$ reported for Asaba Delta state by Ademjumo et al [7], 10.6\% reported by Omote et al., for Jalingo Taraba state [4], 10\% for Ibadan by Ogunbosi et al., [3] and several other reports from Africa countries with rates as high as $15.7 \%$ for Ethiopia [8] and $12.2 \%$ for Zambia [9]. However, our finding of $4.4 \%$ is in consonant with $6.2 \%$ and $2.2 \%$ obtained for two different studies in South Africa [10, 11]. The reduced MTCT rate of $4.4 \%$ recorded in this study and similar rate reported for the two South Africa studies cited above may be may be attributed to the high literacy level of the mothers, high level of ART compliance and improve socio-economic status of the mother as these studies were carried out in areas (Warri, Johannesburg and central area of Durban) with better educational and social indices. Bulk of the participating mothers $(95.6 \%)$ were on ART. This may have contributed to the reduced incidence.

Infants born to mothers on ART gave a $1.3 \%$ MTCT rate. Findings of this study agrees with the report of Cassium and Botha [11] but disagrees with the findings of Imade et al. who recorded $8.6 \%$ for Benin city, Nigeria [2] and Omote et al who obtained $12.5 \%$ for Taraba state, Nigeria [4]. One of the primary risk factor for MTCT is maternal viral load. Increased maternal viral load has been associated with increased MTCT rates. Thus, the 1.3\% MTCT rate recorded may be attributed to reduced maternal viral load as a result of strict compliance with ART. An alarming MTCT rate of $72.7 \%$ was recorded for infant whose mothers did not take ART. The value is far higher than WHO's estimate of $25-45 \%$ and $50 \%$ reported by Omote et al. [4]. Increased viral load in maternal circulation (blood and other secretions) may be responsible for the rate recorded.

Infants on ART and those not on ART gave a similar MTCT rate distribution as recorded for the mothers. This may be attributed to the fact that a similar distribution exist for their percentage of study participants (95.6\%) for mother on ART and $94.0 \%$ for infants on ART. Both findings establish ART as the most important PMTCT intervention.
Infant feeding pattern gave a statistical association with MTCT rate. Infants that were mixed fed (breast fed and also took commercial formula) gave the highest transmission rate of $17.6 \%$. This is in consonant with the findings of Koye and Zeleke for Zimbabwe [12] and Omote et al [4] report for Taraba, Nigeria. These studies highlights mixed feeding as an independent factor associated with MTCT. HIV particle entrance into infant circulation from breast milk is facilitated by an irritated gastro-intestinal tract as a result of the action of the commercial formula on the immature and fragile gastro-intestinal tract.

The issue of infant's sex as a predisposing factor has been controversial with regards to MTCT of the AIDs virus. Several reports $[2,13,14]$ have reported a higher rate for males but this study recorded a $3.2 \%: 5.6 \%$ in favor of the females. This finding is in consonant with other reports $[4,15,16]$.

\section{Conclusion}

The key PMTCT interventions are; ART for infected women, ART for exposed infants, avoidance of breast feeding and caeserian section before the onset of labor or rapture of membrane. Our study assayed for the efficacy of three out of the four mentioned above and our findings indicates a strong association between MTCT and ART status of mother $(\mathrm{p}$-value $=0.00)$, ART for exposed infant $(\mathrm{p}$ value $=0.00)$ and infant's feeding pattern $(0.02)$. The reduced rates recorded when these interventions were used showcases their efficacy and their ability to ensure the elimination of MTCT of the AIDs virus as a public health burden in the nearest future. Augmentation of PMTCT services, increasing the centers and improving access to these facilities and services coupled with enlightenment campaigns to educate the general populace on the availability of these centers, their services and the importance of accessing these facilities and their services is highly recommended. Future studies on the impart of social-economic status of the mother, mother's ART adherence rate, mode of delivery of the infant and educational status of the mother to MTCT is also recommended.

\section{References}

[1] Ezeanolue EE, Obiefune MC, Yang W, Obaro SK, Ezeanolue CO, Ogedegbe GG. Comparative effectiveness of congregation-verse clinic-based approach to prevention of mother-to-child-transmission: Study protocol for a cluster randomized Controlled trial. Implement Sci. 2013; 8 (1): 62.

[2] Imade PE, Uwakwe NO, Omerioge R, Eghasona, NO. Effect of prevention of mother to child transmission program on the prevalence of postnatal HIV infection in Benin City, Nigeria. Sooyin J. Health Sci. 2010; 2 (2): 58-61.

[3] Ogunbosi BO, Oladokun R, Brown BJ, Osinusi KI. Prevalence and clinical pattern of paediatric HIV infection at the University College Hospital, Ibadan, Nigeria: a prospective cross-sectional study. Ital J. Paediatr. 2011; 37:29. 
[4] Omote V, Ojumah I, Etaghene J, Ukwamedua H, Adda D. Mother to child transmission of HIV infection and its predisposing factors among exposed infants on care at Taraba State Specialist Hospital, Jalingo, North-East Nigeria. Asian J. Pharm Health Sci. 2018; 8 (1): 1836-40.

[5] Coovadia HM. Prespectives on paediatric HIV/AIDS: Prevention of mother to child transmission of HIV. Curr Sci. 2008; 95: 9 .

[6] World Health Organization. On the fast-track to an AIDS-free generation. Geneva, Switzerland. 2016. http//emtetiast.org/vop-content/upload/2016/06/Global Plan 2016 en.pdf (Accessed on June, 20,2016).

[7] Adejumo PO, Erhunwuse EO, Oyetunde MO. Utilization of HIV and AIDS mother to child transmission prevention and babies outcome in Asaba, Nigeria. J. Nur Edu Pract. 2014; 4 (2): 178-85.

[8] Wudineh F, Damtew B. Mother-to-child-transmission of HIV infection abd its determinants among exposed infants on care and follow-up in Dire Daiwa, Eastern Ethiopia. AIDS Res and Treat. 2016: (2016), Article ID 3262746, 6 pages.

[9] Torpey k, Mandale J, Kasonde P, Bryan-mosya G, et al. Analysis of HIV early infant diagnosis data to estimate rates of perinatal HIV transmission in Zambia. Plos one. 2012; 7: e42859.
[10] Cassium SM, Botha JH. Prevention of mother to child transmission outcome in the private sector in Central Durban. The South Afri J HIV Med. 2010; 6-7.

[11] Lilian RR, Kalk E, Technan KG, Sherman GG. Birth diagnosis of HIV infection in infants to reduce infant mortality and monitor for the elimination of mother to child transmission. Paediatr Infect Dis J. 2013; 32: 1080-5.

[12] Koye DN, Zeleke BM. "Mother-to-child-transmission of HIV and its predictors among HIV-exposed infants at a PMTCT clinic in North-west Ethiopia”. BMC Public Health. 2013; 13: 398.

[13] Kurewa EM, Kandawajvika GQ, Mhlanga A, et al. Realities and challenges of a five year follow up of mother and child pair on a PMTCT program in Zimbabwe. JAIDS. 2011; 5 (1): $51-8$.

[14] Bakali P, Kayita J, Moura M, et al. Epidemiologic and clinical features of HIV-infected Ugandan Children younger than 18months. JAIDS. 2001; 28 (1): 35-42.

[15] Adejuyigbe EA, Oyelami O, Onayemi O, Durosinmi MA. Paediatrics HIV/AIDS in Ile-Ife, Nigeria. Cent Afri J. Med. 2003; 49 (8): 74-8.

[16] Oniyangi O, Awani B, Iregbu KC. The pattern of Paediatric HIV/AIDS as seen at the National Hospital Abuja, Nigeria. Niger J Clin Pract. 2006; 9 (2): 153-8. 